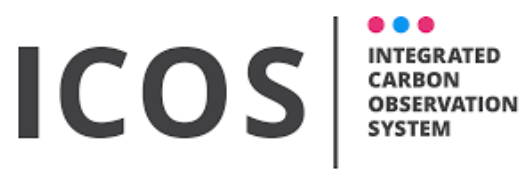

\section{Carbon balance of an intensively grazed permanent grassland in southern Belgium}

The $2^{\text {nd }}$ ICOS Science Conference September, $28^{\text {th }} 2016$

Louis Gourlez de la Motte, Elisabeth Jérôme, Ossénatou Mamadou, Yves Beckers, Bernard Bodson, Bernard Heinesch, Marc Aubinet 


\section{Pasture greenhouse gas budget}

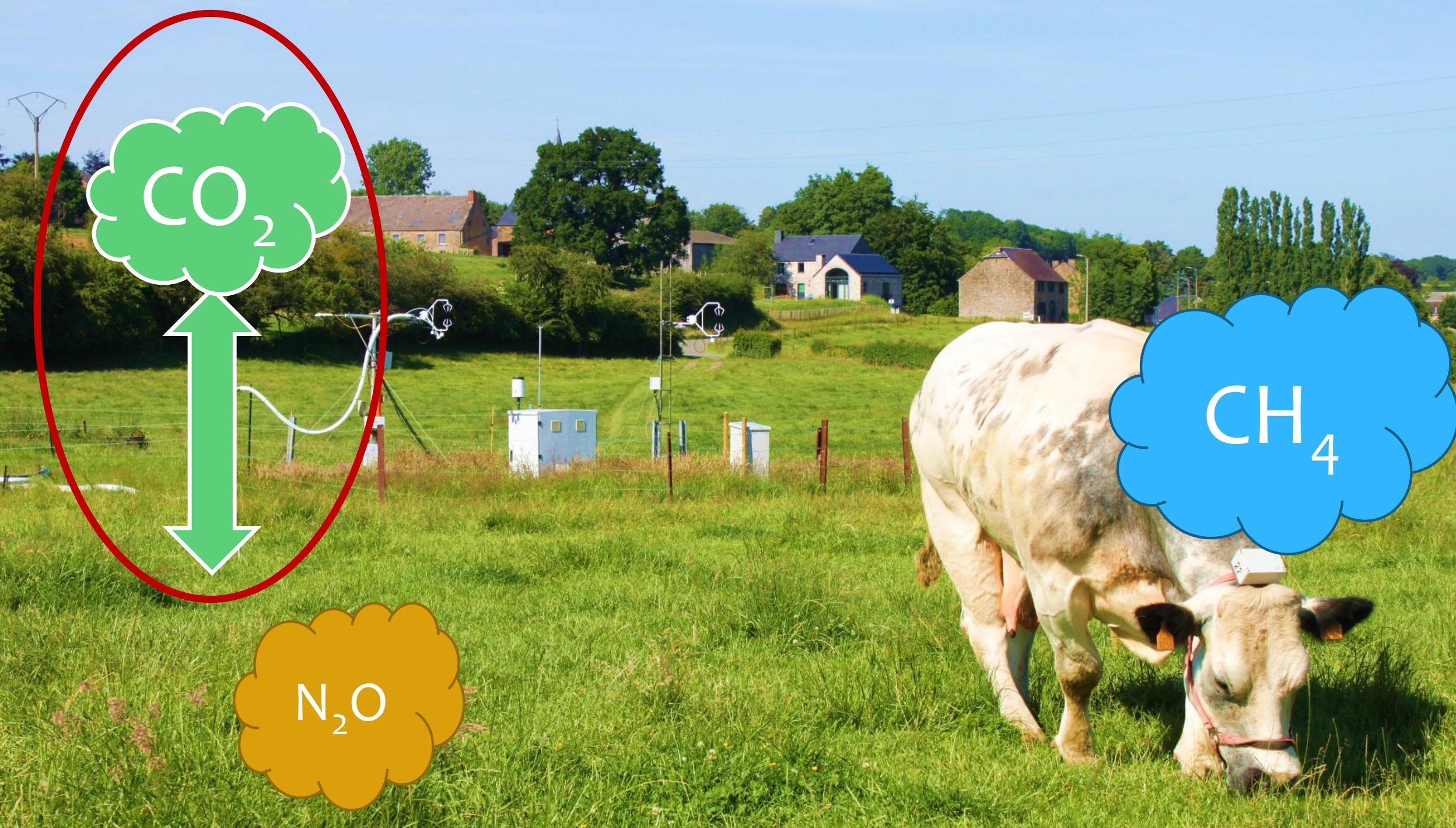




\section{European grasslands carbon balance (Soussana et al., 2007,2010)}

\section{Grazing only}

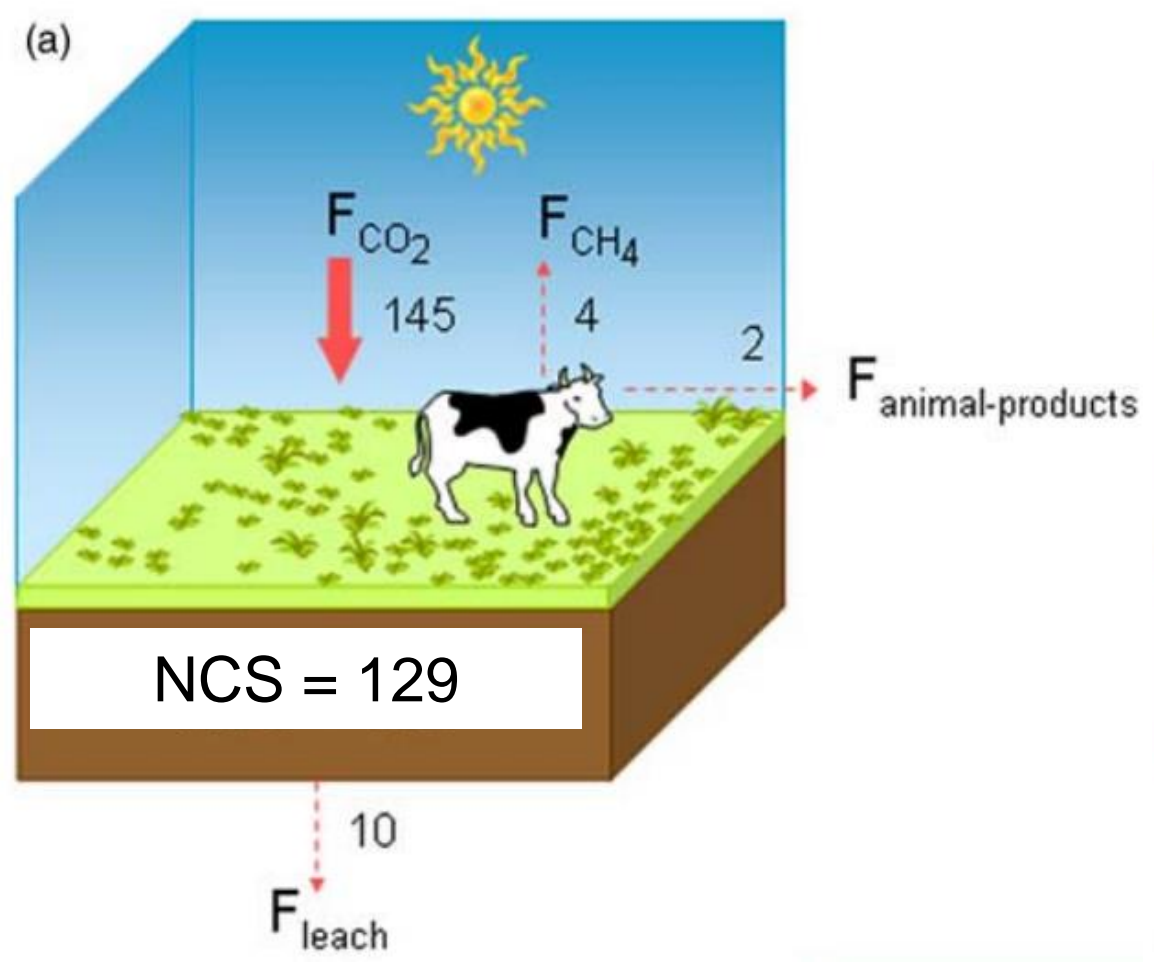

Grazing and harvest

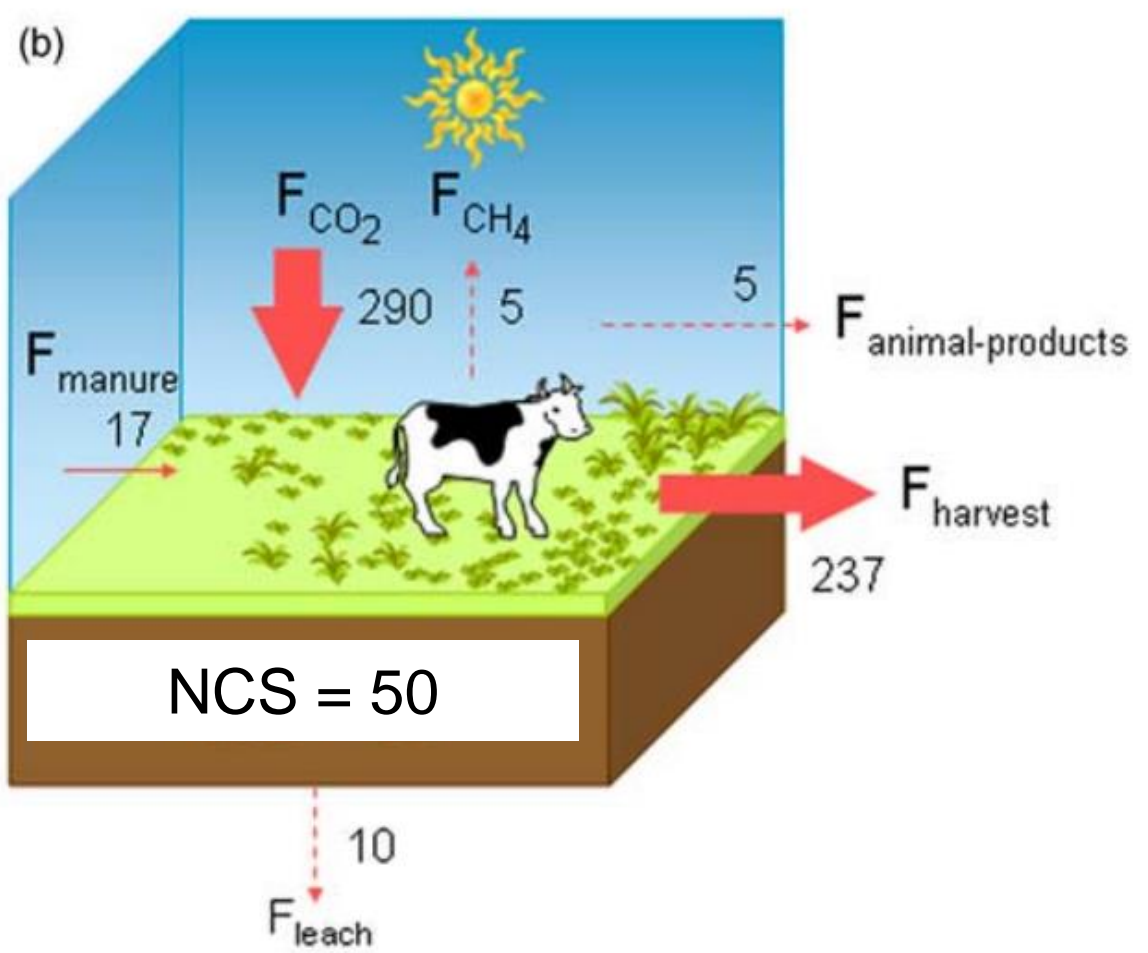

$\checkmark$ Global mean of diversed exploitation (milky cows, goats etc...)

$\checkmark$ Average stocking rate from 0.3 to $1.3 \mathrm{LU} \mathrm{ha}^{-1}$ when grazed

$\checkmark$ Necessity to study a grazing system representative of southern Belgium 


\section{Dorinne: A permanent temperate grassland}

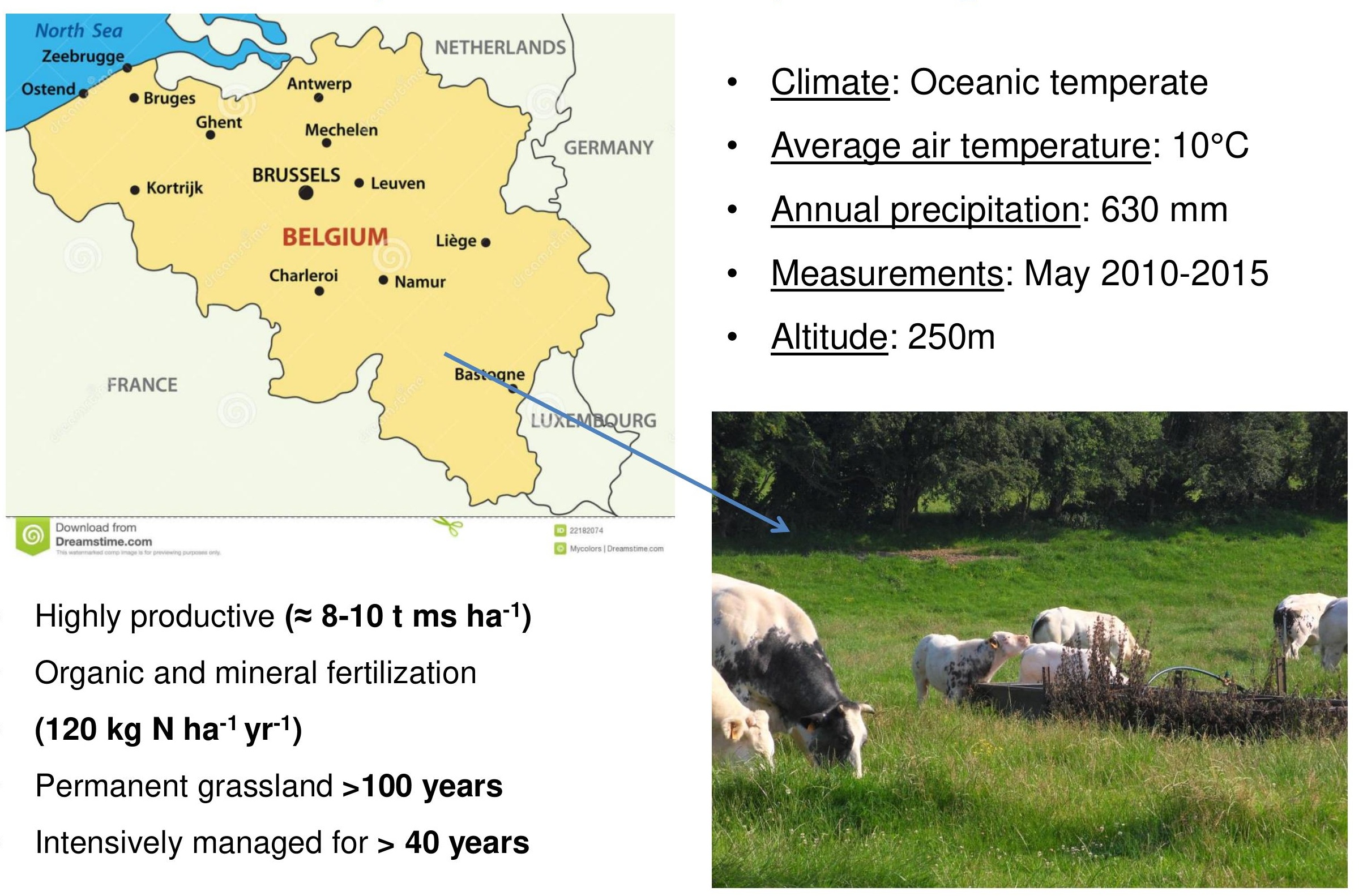




\section{Carbon budget of the pasture}

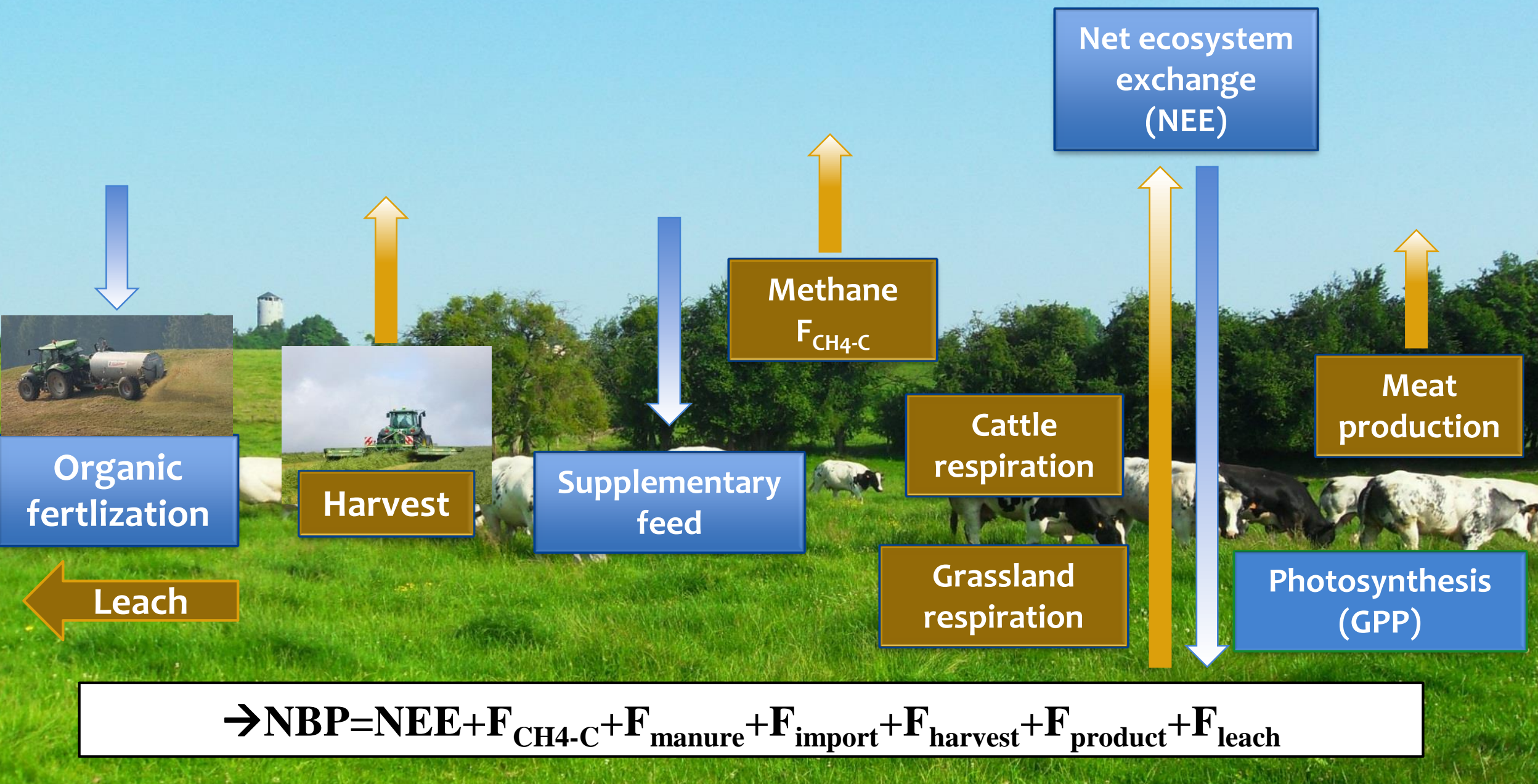




\section{Grazing management}

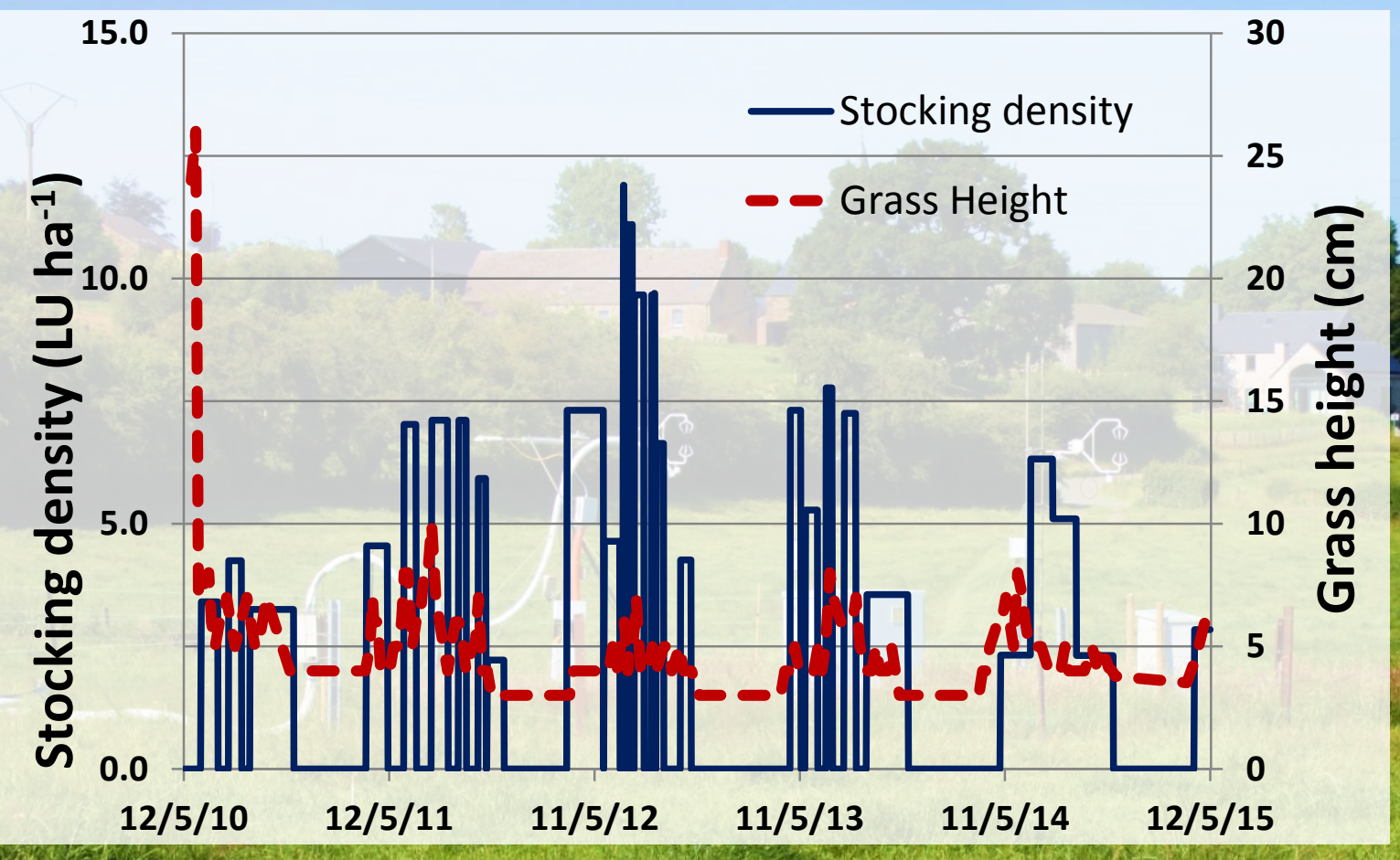

- Average stocking rate $=\mathbf{2 . 3} \mathrm{LU} \mathrm{ha}^{-1}$

- Belgian Blue (meaty cows)

- Organic and mineral fertlization $\left(120 \mathrm{~kg} \mathrm{~N} \mathrm{ha}^{-1}\right)$ 


\section{Sink or source?}

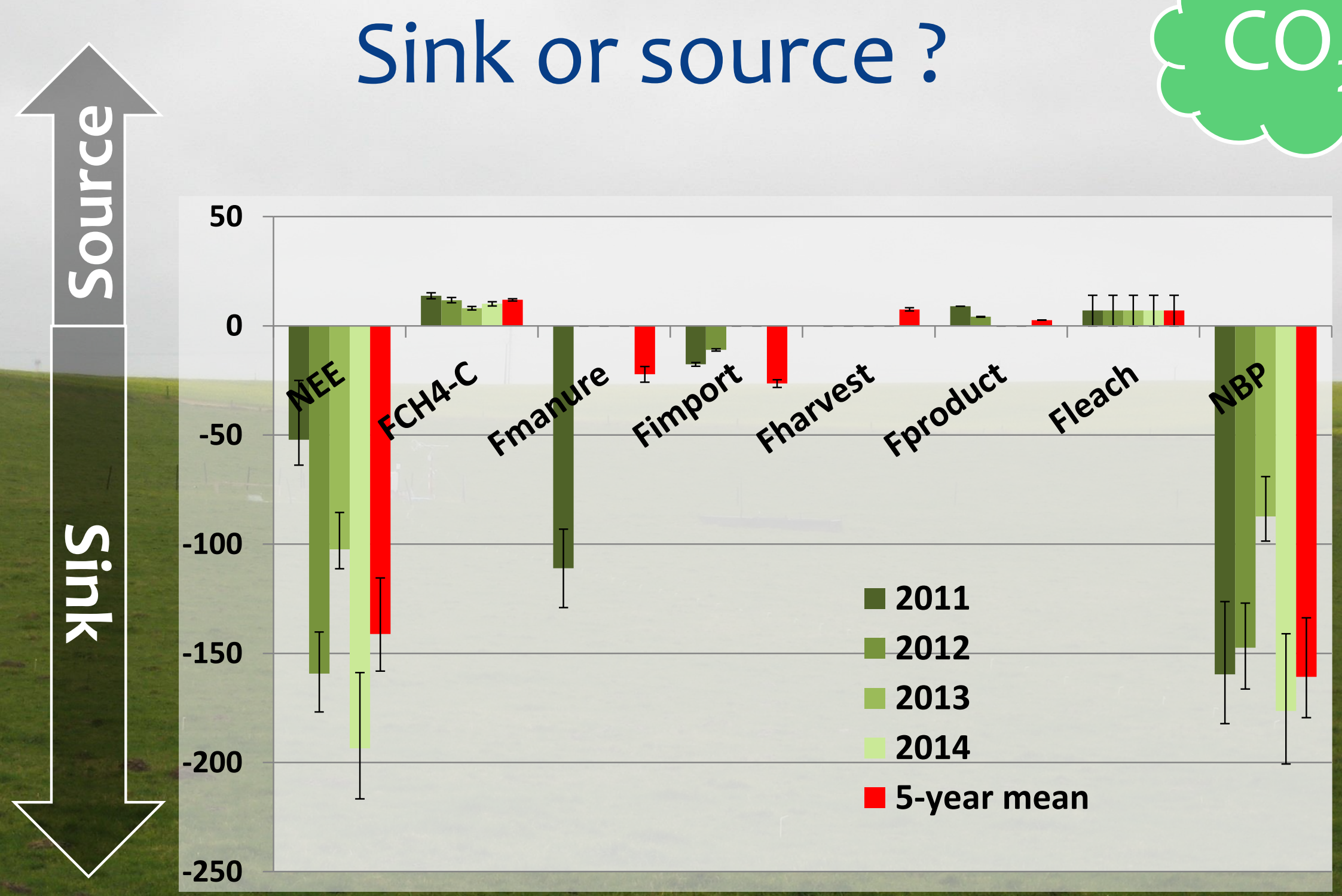

Sink : $-161 \mathrm{gC}^{-2} \mathrm{yr}^{-1}$ on average 


\section{Carbon balance: grazing impact (Jérôme et al., 2014)}

Photosynthesis

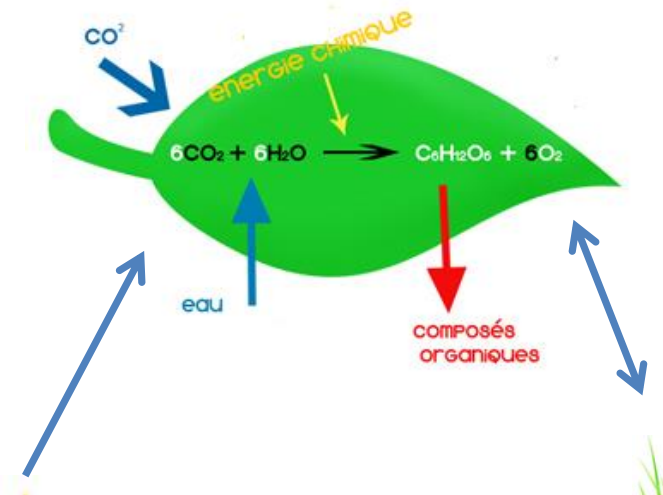

Weather conditions
Biomass
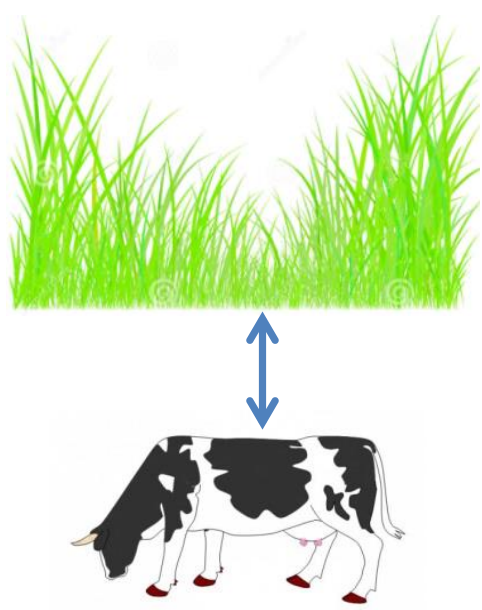

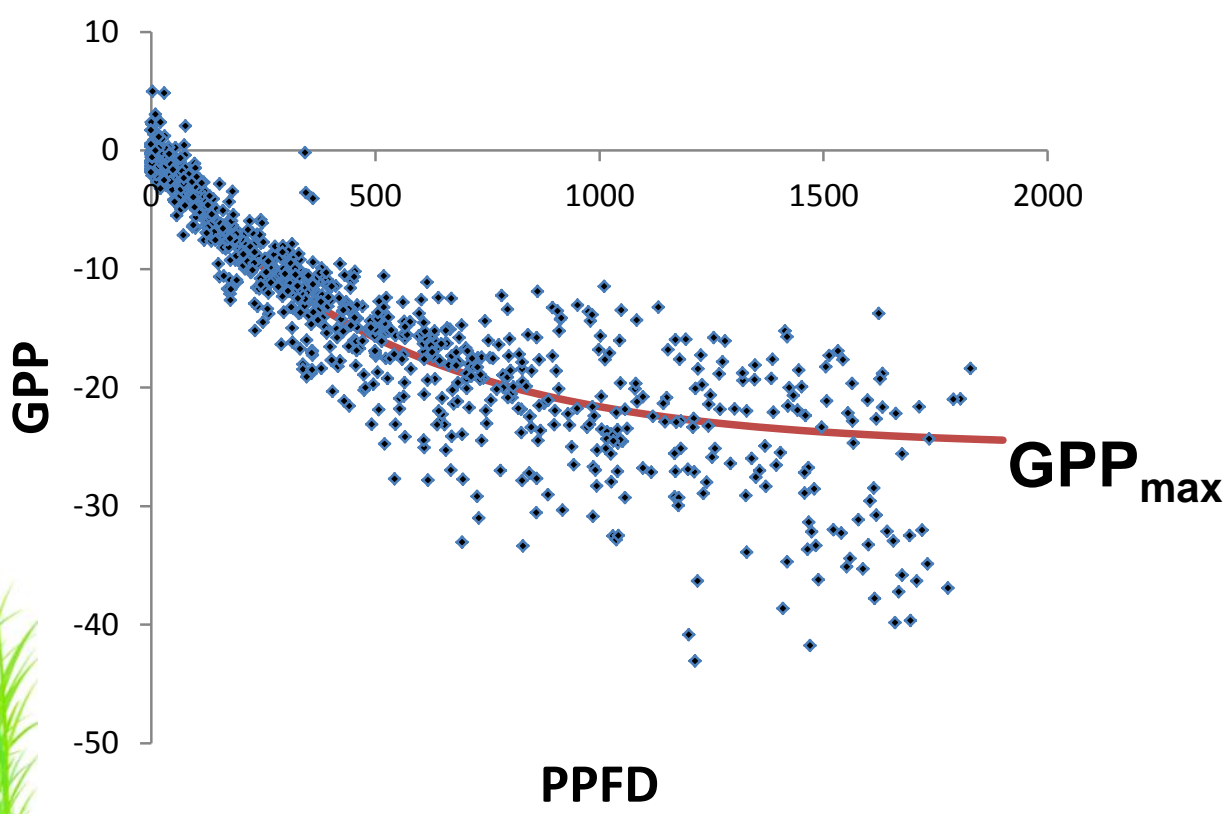

$$
\mathrm{GPP}=\mathrm{GPP}_{\max }\left(1-\exp \left(\frac{\alpha \cdot \mathrm{PPFD}}{\mathrm{GPP} \max }\right)\right)
$$

$\rightarrow$ Relationship between GPP $_{\max }$ and grazing intensity ? 


\section{Carbon balance: grazing impact (Jérôme et al., 2014)}

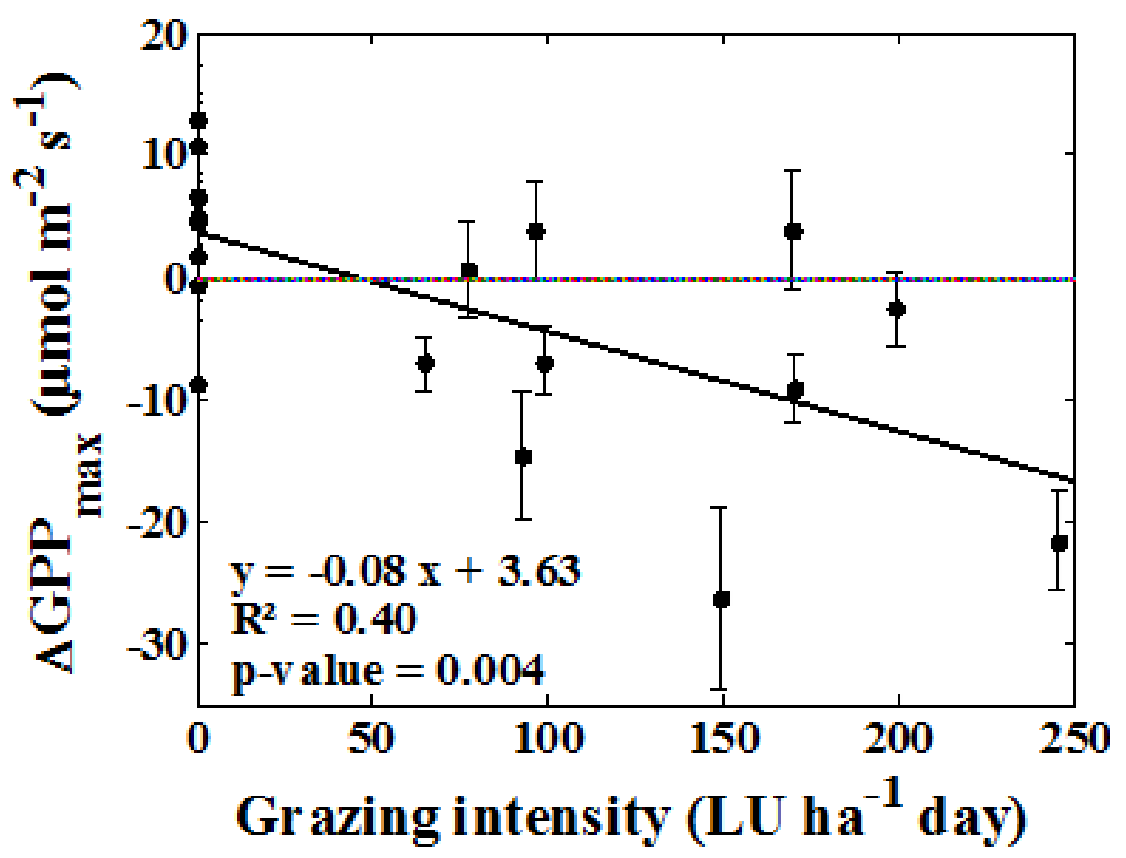

$>$ The decrease of GPP max $_{\text {is negatively }}$ correlated to grazing intensity because of defoliation

$>$ No similar impact was observed on total ecosystem respiration
Photosynthesis

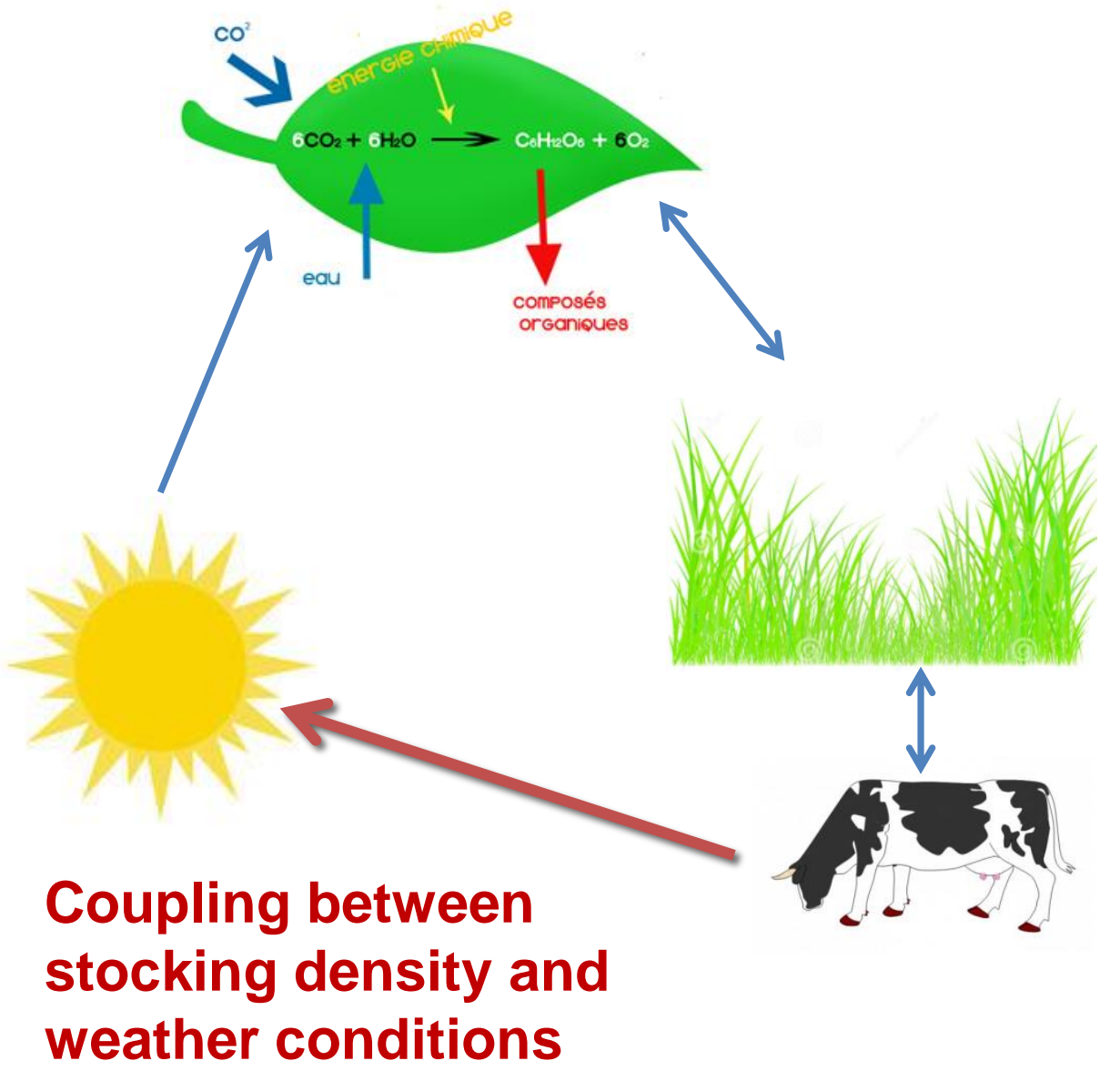




\section{Carbon budget : weather conditions impact}

- No significant relationship between monthly NEE anomalies and weather variables anomalies were observed

- Behavior at least partially due to the coupling between grazing management and weather conditions

- This coupling is necessary to maintain a steady meat production
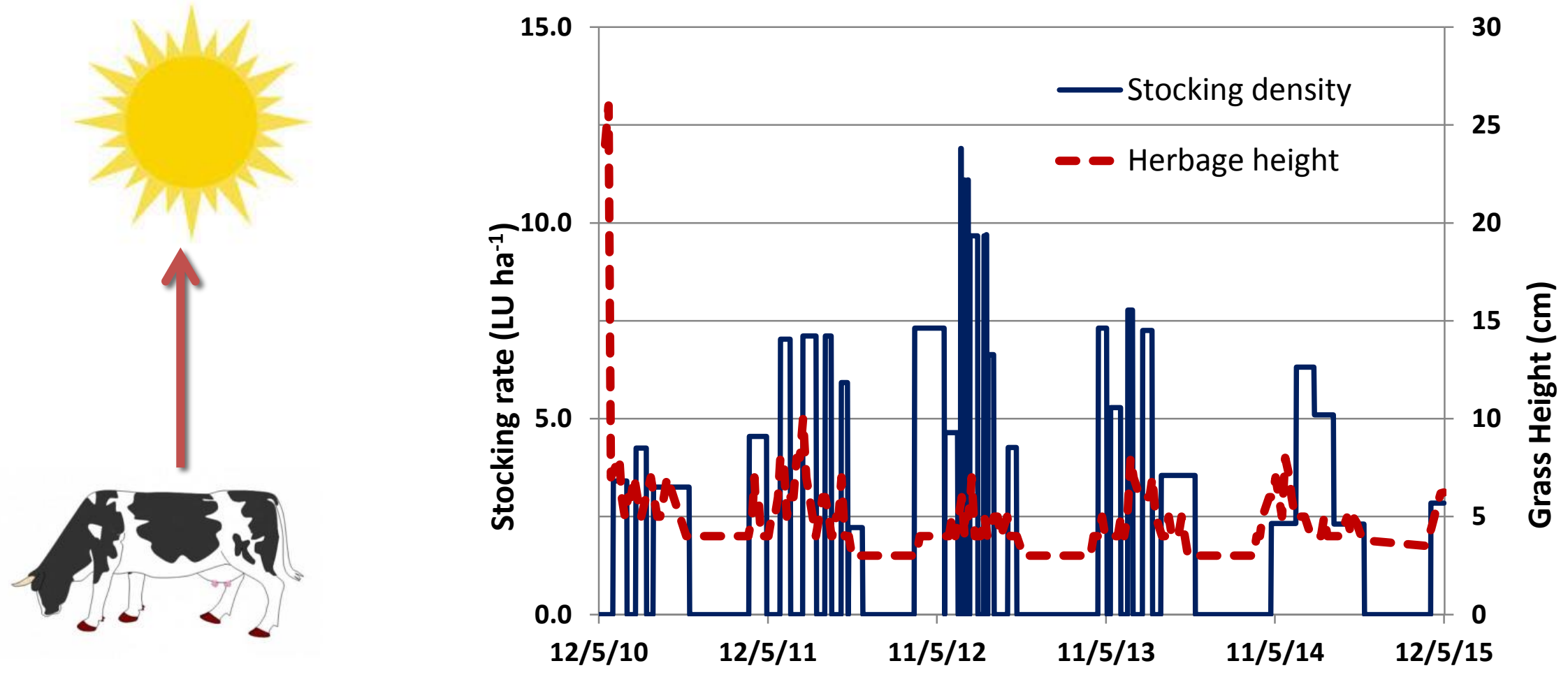


\section{Carbon storage? How long?}

\section{Dorinne grassland}

- Permanent grassland, never cultivated since it is used as a pasture (more than one century)

- Intensively managed with organic and mineral fertilizers since around 40 years

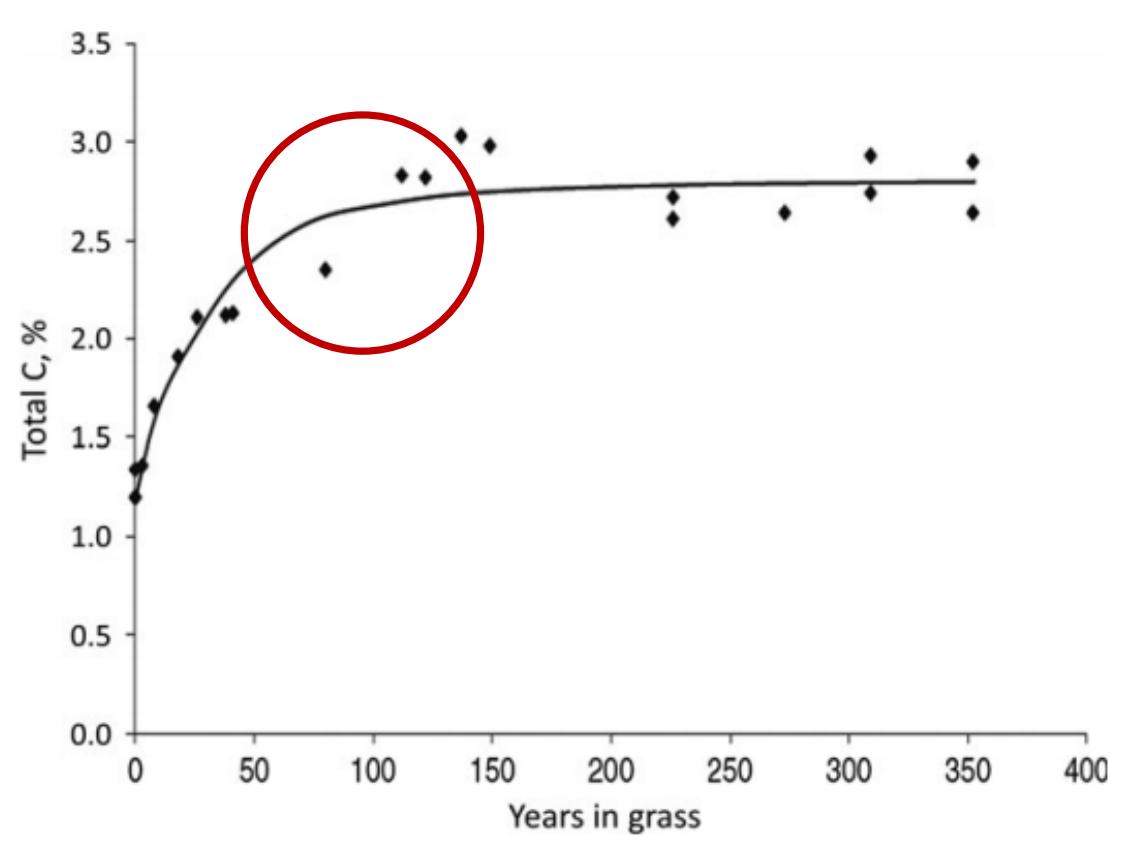

$>$ Carbon stocks stablizes only after around a century

$>$ In agreement with our observations

$>$ There is a strong need to correlate carbon balance observations to carbon stocks

Figure adapted from Johnson et al, 2009 used by Smith et al., 2014 


\section{Conclusions}

- Carbon sink observed every year despite a high stocking rate and the old age of the pasture

- C exports in form of meat were low compared to $C$ exports in dairy pastures

- Probable coupling between weather conditions and grazing management

- Carbon storage that must taken into account in livestock GHG budgets 


\section{References :}

Contents lists available at ScienceDirect

\section{Agricultural and Forest Meteorology}

journal homepage: www.elsevier.com/locate/agrformet

Carbon balance of an intensively grazed permanent grassland in southern Belgium

Louis Gourlez de la Motte $^{\mathrm{a}, *}$, Elisabeth Jérôme ${ }^{\mathrm{a}}$, Ossénatou Mamadou ${ }^{\mathrm{a}, \mathrm{c}}$, Yves Beckers ${ }^{\mathrm{b}}$, Bernard Bodson $^{\mathrm{b}}$, Bernard Heinesch ${ }^{\mathrm{a}}$, Marc Aubinet ${ }^{\mathrm{a}}$

Contents lists available at ScienceDirect

Agriculture, Ecosystems and Environment

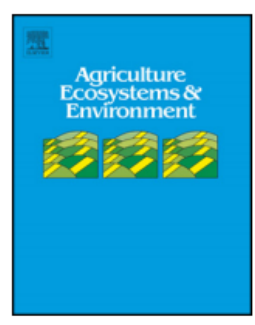

journal homepage: www.elsevier.com/locate/agee

Impact of grazing on carbon dioxide exchanges in an intensively managed Belgian grassland

Elisabeth Jérôme $^{\mathrm{a}, *}$, Yves Beckers ${ }^{\mathrm{b}}$, Bernard Bodson ${ }^{\mathrm{c}}$, Bernard Heinesch ${ }^{\mathrm{a}}$, Christine Moureaux ${ }^{c}$, Marc Aubinet ${ }^{a}$ 


\section{Acknowledgements}

- Adrien Paquet (the farmer)

- Walloon region

- All the co-authors:

Dr. Elisabeth Jérôme, Dr. Ossénatou Mamadou

Pr. Yves Beckers, Pr. Bernard Bodson

Pr. Bernard Heinesch, Pr. Marc Aubinet 